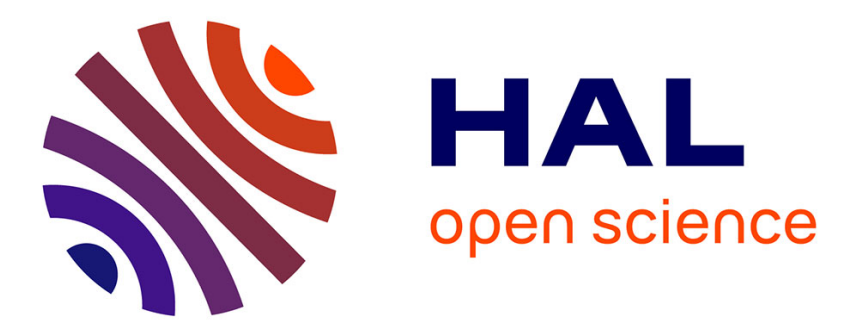

\title{
Analysis of shear stress promoting void evolution behavior in an $\alpha / \beta$ Ti alloy with fully lamellar microstructure
}

N. Dang, L. Liu, E. Maire, J. Adrien, S. Cazottes, W. Xiao, C. Ma, L. Zhou

\section{- To cite this version:}

N. Dang, L. Liu, E. Maire, J. Adrien, S. Cazottes, et al.. Analysis of shear stress promoting void evolution behavior in an $\alpha / \beta$ Ti alloy with fully lamellar microstructure. Materials Science and Engineering: A, 2018, 737, pp.27-39. 10.1016/j.msea.2018.09.032 . hal-01916301

\section{HAL Id: hal-01916301 https://hal.science/hal-01916301}

Submitted on 17 Jan 2019

HAL is a multi-disciplinary open access archive for the deposit and dissemination of scientific research documents, whether they are published or not. The documents may come from teaching and research institutions in France or abroad, or from public or private research centers.
L'archive ouverte pluridisciplinaire HAL, est destinée au dépôt et à la diffusion de documents scientifiques de niveau recherche, publiés ou non, émanant des établissements d'enseignement et de recherche français ou étrangers, des laboratoires publics ou privés. 


\section{Analysis of shear stress promoting void evolution behavior in an $\alpha / \beta$ Ti alloy with fully lamellar microstructure}

Author: Ning DANG ${ }^{\mathrm{a}, \mathrm{b}}$, Lingyu $\mathrm{LIU}^{\mathrm{c}}$, Eric MAIRE*,b, Jérôme ADRIEN ${ }^{\mathrm{b}}$, Sophie CAZOTTES $^{\mathrm{b}}$, Wenlong XIAO*,a, Chaoli MA ${ }^{\mathrm{a}}$, Lian ZHOU $^{\mathrm{d}}$

${ }^{a}$ Key Laboratory of Aerospace Advanced Materials and Performance of Ministry of Education, School of Materials Science and Engineering, Beihang University, Beijing 100191, China

${ }^{b}$ Université de Lyon, INSA de Lyon, MATEIS CNRS-UMR 5510, F-69621 Villeurbanne, France

${ }^{c}$ Baoti Group Co., Ltd., Baoji, 721014, China

${ }^{d}$ Northwest Institute for Nonferrous Metal Research, Xi'an 710016, China

Abstract: With the help of X-ray synchrotron tomography, in situ tensile tests have been performed on Ti-6Al-4V titanium alloy with full lamellar microstructure. The rendered 3D images have shown that void could nucleate as soon as the material yields, although local stress triaxiality $(\mathrm{T}=0.472)$ seems not to be high and even tends to maintain a constant value in the following damage steps $(\mathrm{T}=0.474 \sim 0.510)$. It can be inferred that local stress triaxiality could not be the dominating factor during damage development in this current work. By combining this result with the result of post mortem analysis by SEM and EBSD, it can be found that voids preferentially nucleate and propagate along either the $\alpha / \beta$

\footnotetext{
*Corresponding author.

E-mail: eric.maire@insa-lyon.fr (Eric MAIRE); wlxiao@buaa.edu.cn (Wenlong XIAO)
} 
interface, or along shear bands within one grain/colony, or at grains/colonies boundary. This could be interpreted by the role of shear stress during this processing. Based on the location of voids, shear stress can be taken into consideration at $\alpha / \beta$ interface, shear band within one grain and grains/colonies boundaries, respectively. The origins of shear stress at different scales seems correlated to local microstructure inhomogeneity and subsequent heterogeneous plastic deformation at different scales. Void nucleation and propagation could depend on this local shear stress instead of stress triaxiality.

Keywords: Ti-6Al-4V; Lamellar microstructure; X-ray tomography; Shear behavior; Damage development;

\section{Introduction}

Titanium and its alloys play an important role in modern industries i.e. aerospace, biomedical, and chemical processing and synthesis, due to the integrated properties including excellent mechanical properties, unrivalled corrosion resistance and outstanding biocompatibility[1]. Ti$6 \mathrm{Al}-4 \mathrm{~V}(\mathrm{TA} 6 \mathrm{~V})$, because of its integrated properties and lower cost, is considered as the most common titanium alloy[2,3]. Depending on the thermo-mechanical treatment or heat treatment of such $(\alpha+\beta)$ titanium 
alloy, the microstructure morphologies or mechanical properties may vary in a wide range [3]. It is well recognized that the mechanical properties are mainly dependant on microstructural features; furthermore, failure behavior of $\mathrm{Ti}$ alloys could be affected by these features significantly $[3,4]$.

Depending on the thermo-mechanical treatment of such $(\alpha+\beta)$ titanium alloy, different microstructures can be obtained, which can lead to different mechanical properties[5-7]. Two extreme microstructure morphologies are fully lamellar microstructure and equiaxed microstructure. The fully lamellar microstructure could present a lower strength and lower ductility, but better fatigue crack propagation resistance; whereas the equiaxed microstructure can show a better initiation fatigue crack resistance. Any bimodal microstructure is a combination of equiaxed and lamellar microstructures that combine both mechanical properties and can present well-balanced fatigue properties.

From the literature it can be noticed that most of researchers' attention was paid on fully equiaxed[8-13] or bimodal microstructure[1416] rather than fully lamellar microstructure[17,18]. However, after casting or welding process, the existence of fully lamellar microstructure cannot be avoided. In order to enhance the mechanical properties of components with this structure, it is necessary to focus on the failure 
mode of TA6V presenting a fully lamellar microstructure. Because TA6V is consisting of $\mathrm{HCP} \alpha$ phase and $\mathrm{BCC} \beta$ phase, microstructural inhomogeneity is inevitable. This may induce an inhomogeneous stress/strain distribution, which could play a key role in the ductile damage evolution [19].

In order to describe this microstructure inhomogeneity and consequently, heterogeneous stress/strain distribution at micro-scale, microstructure-based micromechanical modeling approach can be adopted [13,20-24]. Consequently, numerous models were proposed and validated to elucidate micromechanical behavior with microstructure features for dual phase metals, especially for dual phase steels[20-24].

As indicated by Q.Xue et al [25], microstructure inhomogeneity, internal boundary and favorable orientation of grains or colonies could affect the distribution of strains which could determine the site for shear band formation, on which void nucleation occurs. Because of local constraints induced by microstructure distribution heterogeneities, heterogeneous void growth can be found for Ti-6Al-4V alloy during damage development [13]. Unfortunately, up till now, for TA6V dual phase titanium alloys, the micro-mechanism of heterogeneous stress/strain distribution and its acting on damage evolution is not completely known.

This work aims at deepening our understanding in the origins of 
plastic deformation inhomogeneities and its role in the failure processing of TA6V alloy. Based on the authors' previous work [26], ductile damage, a process driven by plastic deformation, is the main failure mode for such alloy. It is commonly proved that the procedure can be divided into three steps[16], void nucleation, void growth and void coalescence. With the help of 3D tomography technology, it is possible to investigate the action of such heterogeneities in the development of ductile failure. [13,26-29].

Hence, in the present work, in situ tensile tests are carried out based on synchrotron X-ray micro-tomography for Ti-6Al-4V alloy with a fully lamellar microstructure in order to track and analyze void evolution. Then, post mortem procedure are performed by scanning electron microscopy(SEM) and electron backscatter diffraction (EBSD) in order to analyze the micro-mechanism of plastic deforming heterogeneities in terms of microstructure inhomogeneities. Then, shear behavior, correlated with such plastic deforming heterogeneities, is analyzed at the microscale and grain-scale. This leads to the formation of micro-shear band, shear band initiation or neighbor grains /colonies rotation, respectively. The influence of these shear induced mechanisms on void nucleation and propagation are also analyzed and interpreted in this work. 


\section{Experiments}

\subsection{Materials}

In order to obtain fully lamellar microstructure, commercially available casting Titanium Ti-6Al-4V alloy, fabricated by BaoTi Group Co.Ltd was investigated in the form of plates, with a dimension of $300 \mathrm{~mm} \times 200 \mathrm{~mm} \times 10 \mathrm{~mm}$. The chemical composition of the material, in $\mathrm{wt} \%$ is $6.43 \mathrm{Al}, 4,21 \mathrm{~V}, 0.40 \mathrm{Fe}, 0.15 \mathrm{Si}, 0.10 \mathrm{C}, 0.05 \mathrm{~N}, 0.015 \mathrm{H}$ and bal. Ti. In the subsequent heat treatment, the solution-aging parameters were selected based on the $\beta$-transus temperature $\left(995^{\circ} \mathrm{C} \pm 5^{\circ} \mathrm{C}\right)$. This TA6V plate was treated at $960^{\circ} \mathrm{C}$ for 1 hour followed by air cooling and aging treatment in order to obtain fully lamellar structure. Then the plate was aged at $540^{\circ} \mathrm{C}$ for 8 hours following air cooling to ensure equilibrium distribution of $\alpha / \beta$ phase.

For the subsequent analysis, TA6V samples were cut from the plate with the size of $35 \mathrm{~mm} \times 10 \mathrm{~mm} \times 10 \mathrm{~mm}$ for manufacturing the samples for microstructure observation and in-situ tensile test. Phase composition and microstructure morphology produced by this treatment are illustrated in Fig.1. Only $\alpha$ phase could be noticed in the result of $\mathrm{XRD}($ Fig.1(a)), this may relate to the very small amount of $\beta$ phase in the sample. However, as shown in Fig.1(b)\&(c), $\beta$ laths can be clearly observed. 

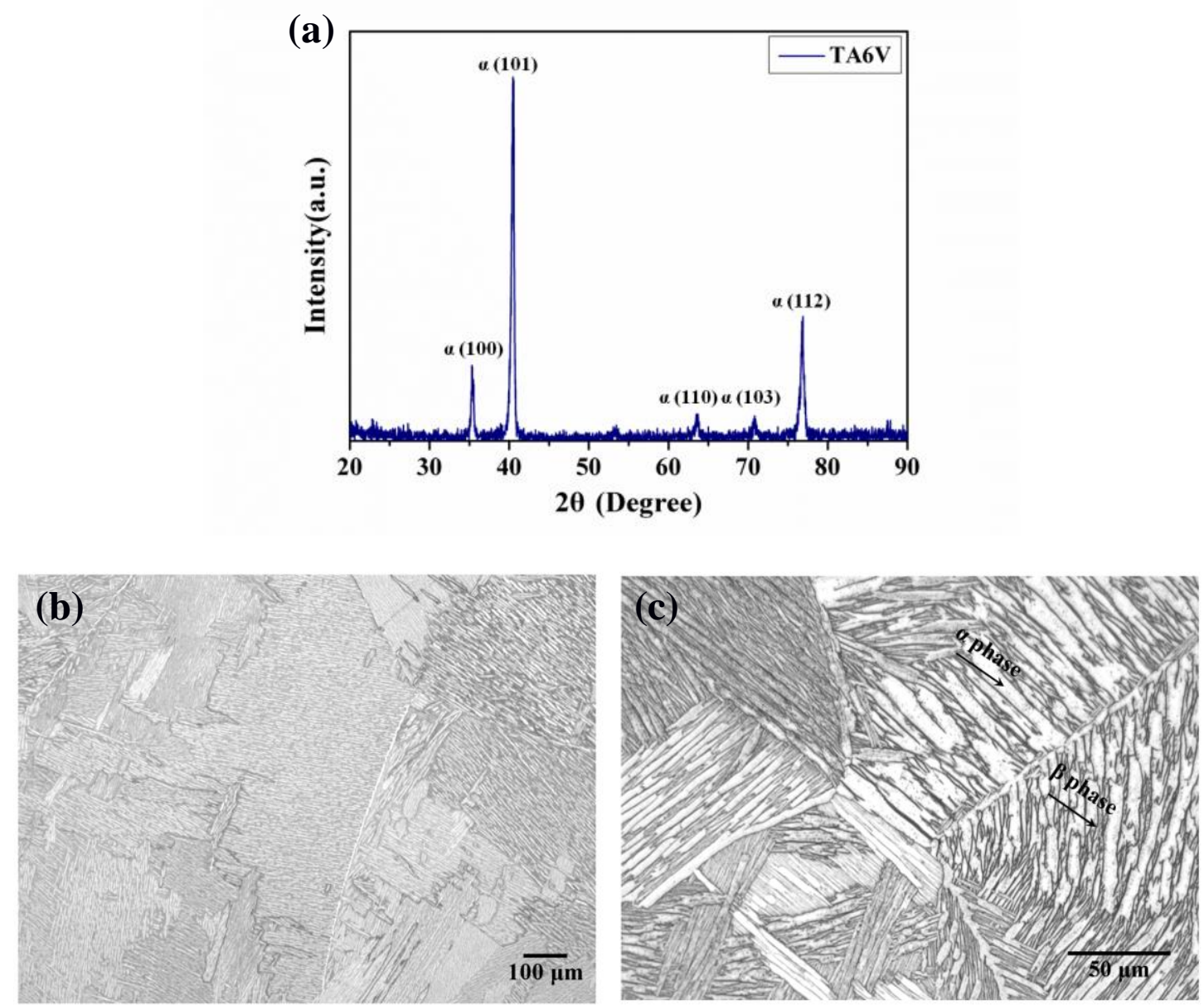

Figure1. X-ray diffraction spectrum(a), microstructure morphology at low magnification (b) and high magnification (c) for the Ti-6Al-4V sample before deformation ( $\alpha$ phase in bright, and $\beta$ phase in dark)

\subsection{X-ray tomography}

Tomography measurements were performed at the ID19 beamline at the European Synchrotron Radiation Facility(ESRF) in Grenoble, France. More details on the set-up can be found in Ref.[27.30]. The spatial resolution and voxel size of the tomography can be achieved up to $1 \mu \mathrm{m}$ 
and $1.3 \times 1.3 \times 1.3 \mu^{3}$, respectively. A dedicated in situ tensile test apparatus (in Ref.[27,30]) was mounted on the rotation stage of the tomography set-up.

Before deformation, one scan was carried out to capture the undeformed state. Hereafter, several scans were performed until the sample fractured. It is worth noting that the loading was stopped but not released during each scanning procedure. Although continuous tensile experiments based on tomography have become available; our step-bystep procedure, give results comparable with those coming from a continuous loading procedure $[31,32]$.

\subsection{In situ tensile test}

For in situ tensile test based on X-ray tomography, the shape of the samples, inspired by Landron et al [29], were cut into $2.5 \mathrm{~mm}$ radius notched samples. The geometry of the samples is given in Fig. 2 .

(a)

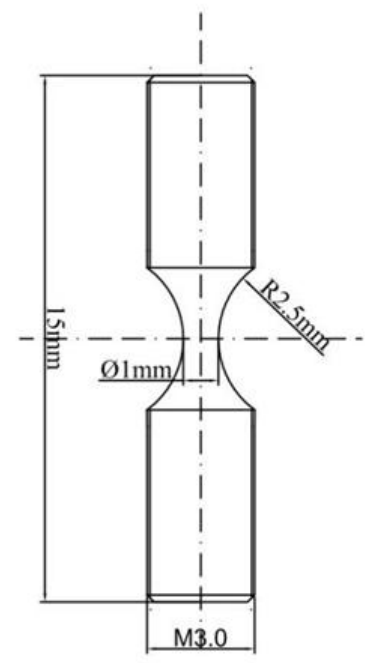

(b)

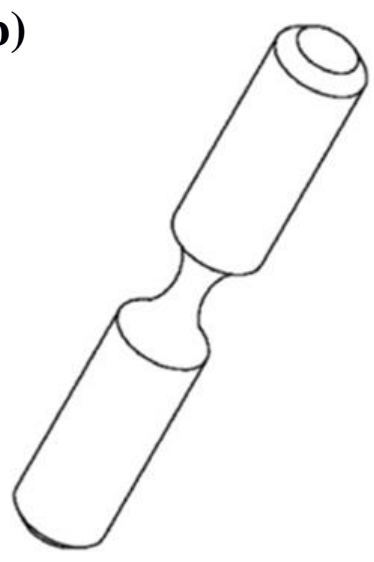

Figure.2 Schematic illustration of tensile sample, (a) geometry of the 
sample,(b) 3D view[33]

The local strain, $\varepsilon_{\mathrm{loc}}$, during deformation was calculated as

$$
\varepsilon=\ln \left(\frac{S_{0}}{S}\right)
$$

where $S_{0}$ is the area of initial cross-section in the undeformed state, and $S$ is the solid area of minimal cross-section at each damage step. This means that in the measurement of $\mathrm{S}$, the eventual area of the voids in the current section is subtracted. The minimal cross-section $\mathrm{S}$ was also used to evaluate the true stress in this section,

$$
\sigma_{\text {true }}=\frac{F}{S}(2)
$$

where $\mathrm{F}$ is the measured force during the tensile test.

Fig.3(a) and (b) present the force-displacement and true stress-strain curve which were obtained in this in situ tensile deformation. It should be noticed that different loading rates were set for elastic deformation and plastic deformation, individually. Within elastic deforming period, the loading rate was set to $5 \mu \mathrm{m} / \mathrm{s}$. With the onset of plastic deformation, because of limited plastic capacity for this alloy, the loading rate was decreased $(0.1 \mu \mathrm{m} / \mathrm{s})$ in order to perform more scans. In this current work, the first scan was performed at the yielding point, while the last one was carried out just before the fracture (shown in Fig.3(a)\&(b) ). 
(a)

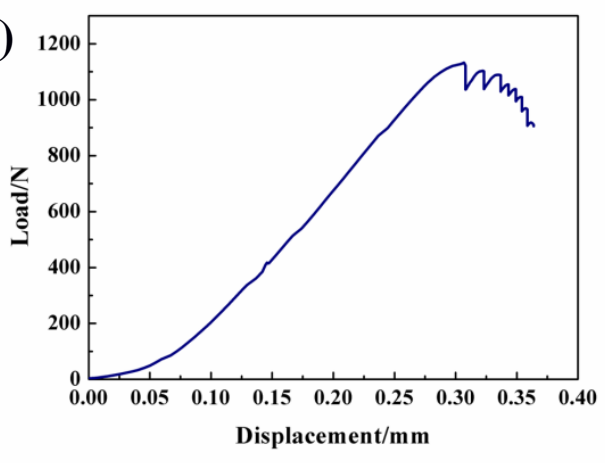

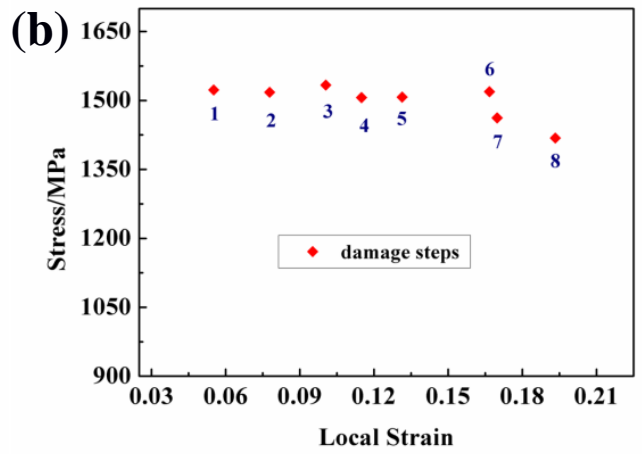

Figure.3 Force-displacement curve (a) and scanning points (b) of TA6V sample[26]

\subsection{Microscopic measurement for X-ray tomography data}

After this tensile test, damage was quantified according to the postprocessing procedure for dual-phase steel presented in $[27,29,34]$. The raw data obtained from reconstructed volumes were median filtering and thresholding, based on the approach described in [29]. This procedure allows us to distinguish the voids from the TA6V matrix.

Only the central region of the tensile specimen is selected for damage analysis, according to T. Pardoen and F. Delannays' work[35], which indicates that the central volume undergoes the largest stress triaxiality and highest strain that leads to the fastest damage rates. The post treatment and 3D rendering work was managed by using open source image analysis software, Image $J$ and Tomviz. 


\subsection{Post mortem based on SEM}

After fracture, the samples were embedded into epoxy matrix parallel to their tensile direction, followed by polishing down to the central plane. The surfaces were grinded by using $\mathrm{SiC}$ paper up to 2500 grade. Then, the surfaces were polished and etched by a mixed solution of OP-S and $\mathrm{H}_{2} \mathrm{O}_{2}$ and Kroll's reagent ( $1 \mathrm{ml} \mathrm{HF}+3 \mathrm{ml} \mathrm{HNO}_{3}+96 \mathrm{ml}$ water $)$. Both microstructure and voids, were observed by SEM (Zeiss Supra 55VP). High resolution EBSD analysis was conducted in this SEM equipped with Oxford Instrument Nordlys detector and the Aztec online acquisition software package. A free tool — "Analysis Tools for orientation Mapping"(ATOM) was used for EBSD data post-processing[36].

\section{Results}

\subsection{Microstructure morphologies}

Before deformation, a full lamellar microstructure morphology can be observed (seen in Fig.1 (b)\&(c) ). The samples comprises colony microstructure with a prior- $\beta$ grain size (and comparable colony size) of $500 \sim 800 \mu \mathrm{m}$ and a grain boundary $\alpha$ layer approximately $3 \sim 5 \mu \mathrm{m}$ thick. After deformation, as shown in Fig.4, the sample still tends to maintain fully lamellar microstructure morphology. However, microstructure 
distortion can be clearly observed which means that severe plastic deformation exists within this local region. The tensile direction was parallel to the horizontal direction of this Figure.
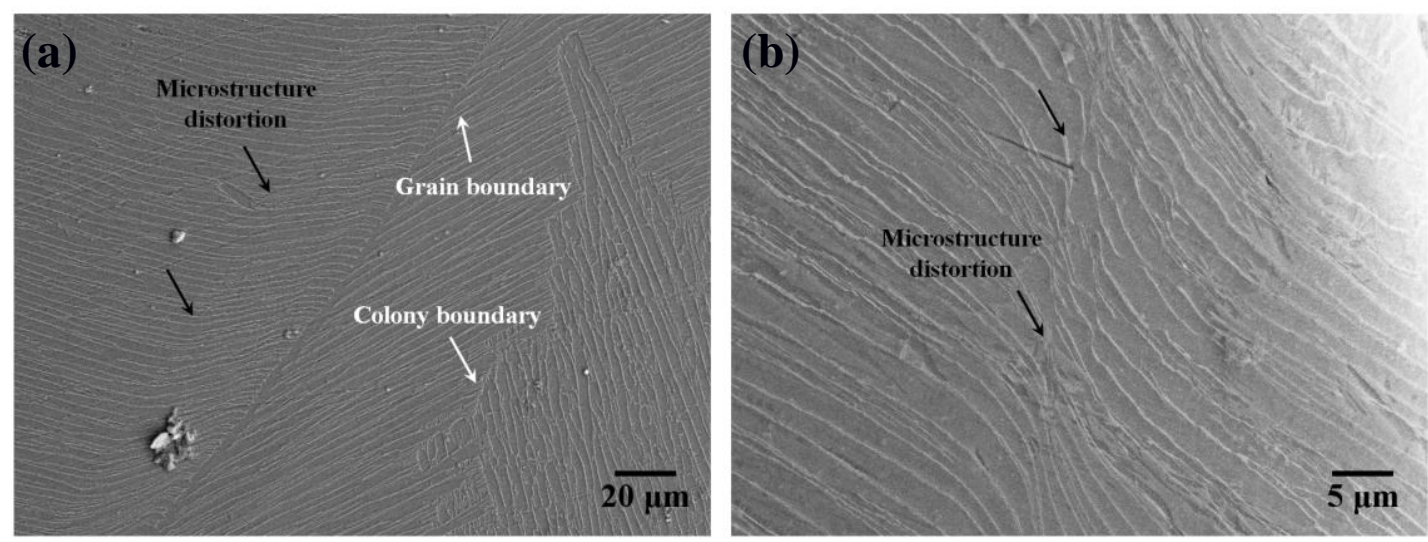

Figure.4 Microstructure morphology for the Ti-6Al-4V sample after deformation in low magnification(a) and high magnification(b).

\subsection{X-ray tomography}

Fig.5 presents the typical evolution of the reconstructed vertical section of the sample. These sections are extracted from the $3 \mathrm{D}$ volume at different damage steps. These refer to undeformed step(a), just after yielding(b), void coalescence step(c) and just before fracture(d). The orientation of these sections is parallel to the tensile axis, which is vertical in this figure.

Within this figure, only one crack can be observed and the growing direction of this crack seems to be perpendicular to the tensile axis. Meanwhile, in order to understand void evolution deeply, 3D 
reconstructed images are presented in Fig.6.
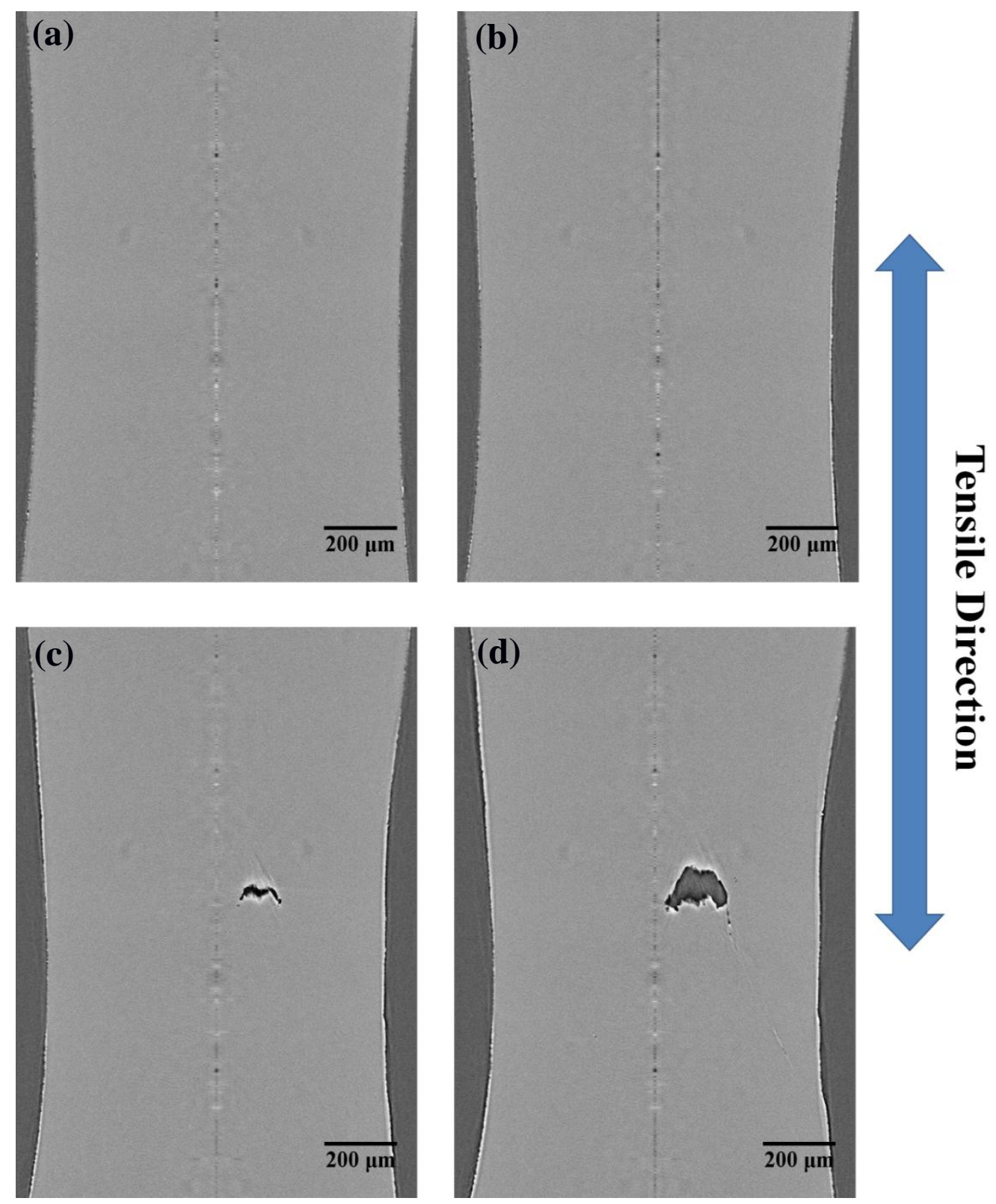

Figure.5 Tomographic slices parallel to the tensile axis at different damage steps. (a) undeformed step, (b) just after yielding, (c) void coalescence step and (d) just before fracture

Fig.6 shows a 3-D reconstructed volume for the imaging area at the same damage step as in Fig.5. In this figure, the matrix is transparent and the outer aspect of the sample is visualized in a semitransparent mode. As 
shown in Fig.6(c), the main crack formed could lead to final fracture in the following steps.

It is interesting to note that in previous work concerning damage analysis of other ductile metals, such as dual phase steels[27,29,34] or $\mathrm{Al}$ alloys[31-33], obvious necking behavior can be noticed during the deformation procedure. While slight necking phenomenon can be found within Fig.5 \& Fig.6, it may symbolize the discrepancy of damage evolution between TA6V in this current work and other ductile metals. In addition, comparing with voids number of DP steels[27,29,34] or Al alloys[31-33] in the literatures, only few voids could be observed in Fig.6. This could be associated with microstructure morphology and micromechanism of deformation for this alloy. Details will be given in a following section of this paper. 

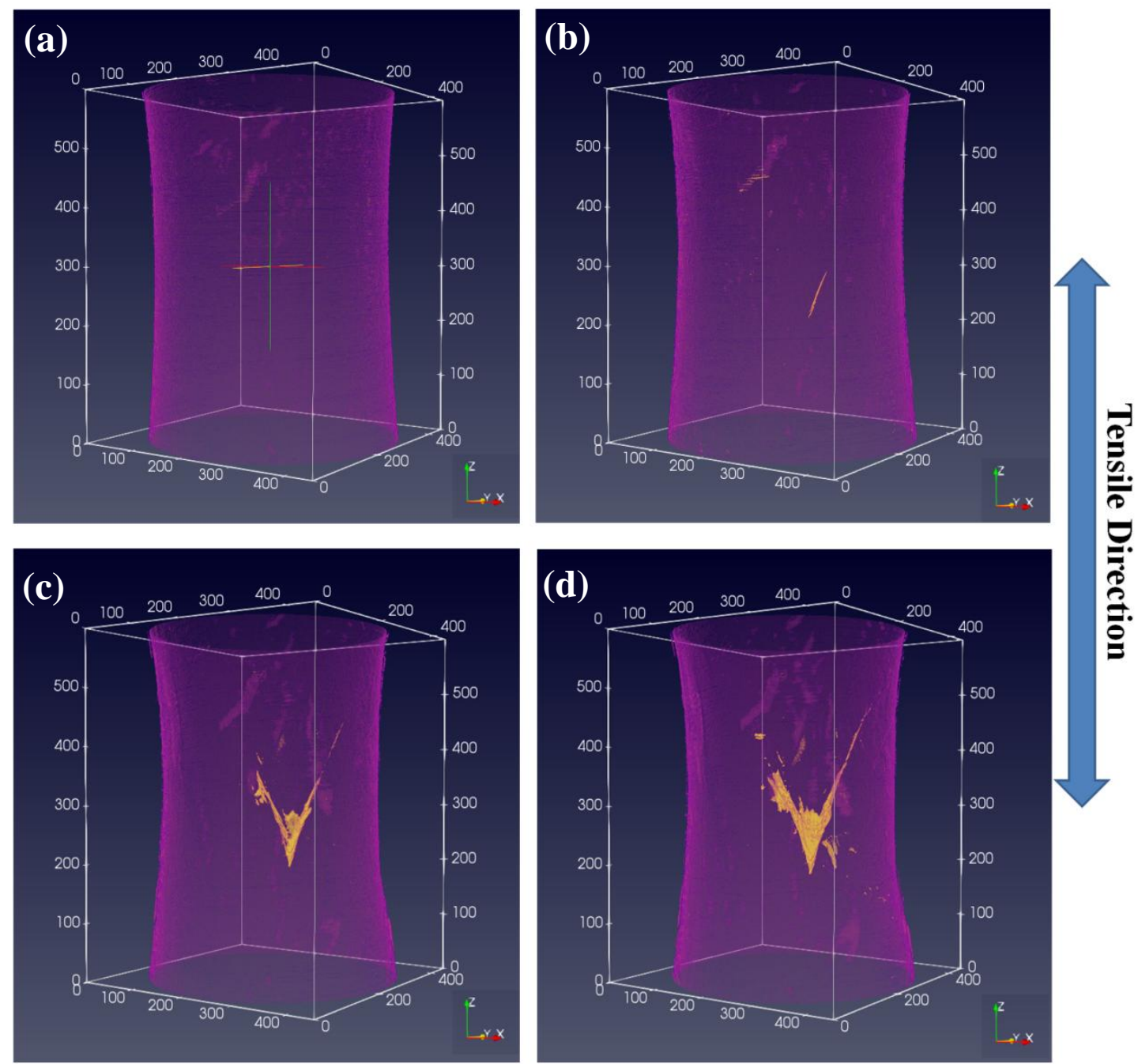

Figure.6 3-D presentation of the reconstructed volume for the sample in

(a) undeformed step (b) just after yielding (c) void coalescence step (d) just before fracture. The dimension of the reconstructed block is $450 \times 450 \times 600$ pixel $^{3}\left(1095 \times 1095 \times 1460 \mu \mathrm{m}^{3}\right)$. The perspective view makes the insertion of a scale bar inappropriate.

\subsection{Microscopic damage measurement}

The curvature radius of outer surface $\mathrm{R}$ and the radius of the minimal section $r$ can be used to calculate the average stress triaxiality $\mathrm{T}$ in the 
center of the minimal cross-section with the help of Bridgman formula[37],

$$
\mathrm{T}=\frac{1}{3}+\ln \left(1+\frac{r}{2 R}\right)
$$

It has been proved that local strain calculated from Eq.(1) and stress triaxiality calculated from Eq.(3) exhibit acceptable agreement when comparing with the results from finite elements simulations[29].

Fig.7 shows development of stress triaxiality $\mathrm{T}$ as a function of local strain during the deformation. It can be seen that, although severe plastic deformation occurs in the minimal section region, the value of $\mathrm{T}$ tends to maintain a low and constant value $(\mathrm{T}=0.474 \sim 0.510)$. This is due to slight necking.

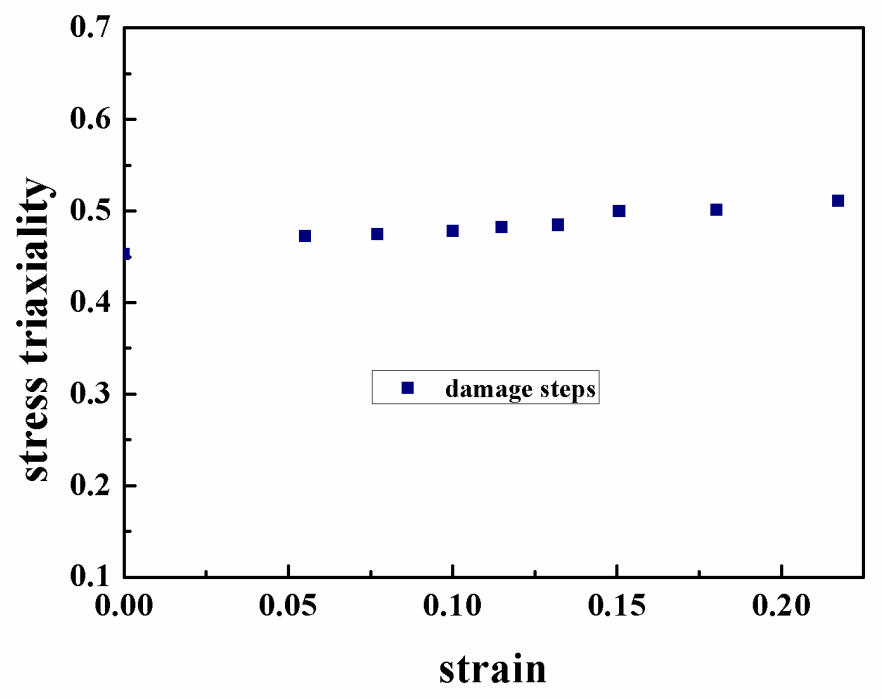

Figure.7 The stress striaxiality as a function of the local strain, calculated by the Eq.(3).

In modern damage models, including commonly used Rice-Tracey 
model(R-T model)[38] and Gurson-Tvergarrd-Needleman model(GTN model) $[39,40]$, stress triaxiality(T) is considered as an important factor in void evolution processing. According to Helbert's work[12], for Ti-6Al$4 \mathrm{~V}$ alloy, stress triaxiality, which could affect void evolution significantly during void development, can be reflected by the angle between stress axis and void growing direction. This angle could increase with the increase of triaxiality value, which can lead to the damage mode transformation, from plastic instability to cleavage mode.

As shown in Fig.8, it can be clearly seen that the angle tends to maintain a constant value during damage development. In Fig.8(a), one void is observed tilting at about $23^{\circ}$ to the stress axis. While in Fig.8(b) and (c), with the increase of plastic deformation, another void is generated (see Fig.8(b) ) and it then coalesce to the former one (see Fig.8(c) ). Comparing the result of Fig.8(b) with (c), it can be found that this latter void intends to grow in the direction which is inclined $28^{\circ}$ towards stress direction.
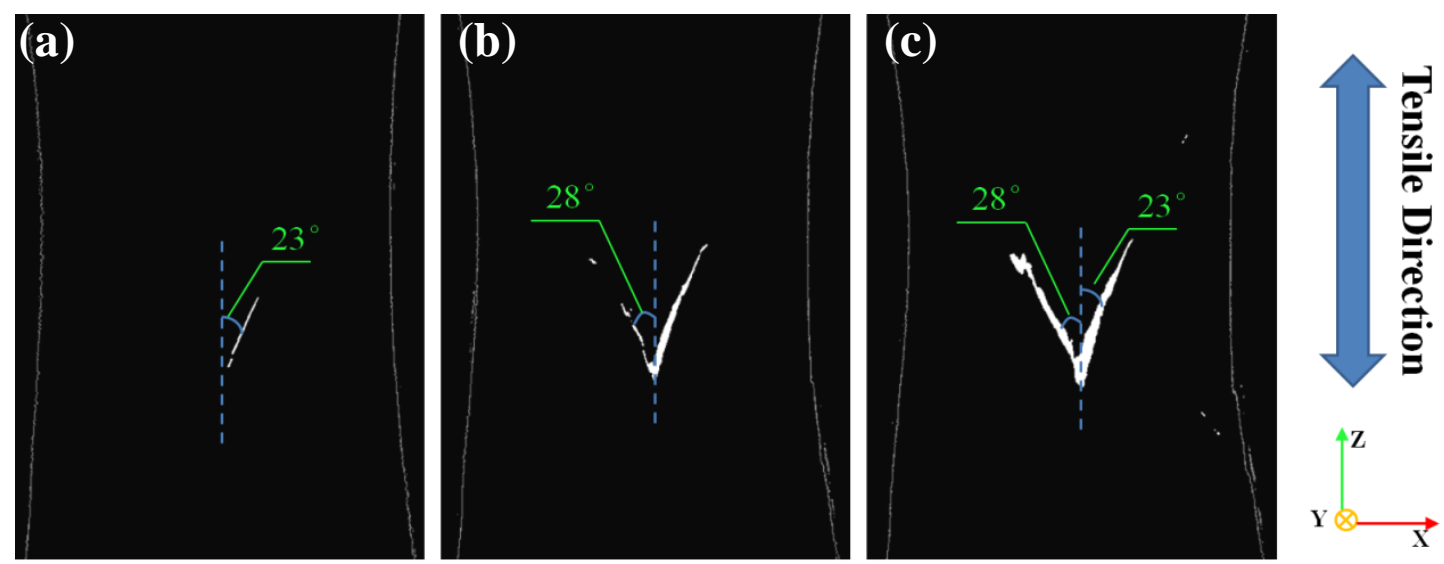

Figure. 8 presents the variation in angle between stress axis and void 
growing direction, which were extracted from the tomographic 3-D block in the same damage steps as Fig.6, (a) just after yielding (b)void coalescence step (c)just before fracture.

\subsection{Post mortem based on SEM \& EBSD}

3D X-ray tomography could show interesting advantages in analyzing void evolution, including size, aspect and position; however, it also presents a lack of capacity to observe microstructure morphology of such TA6V alloy. Hence, in order to focus on the dependence of damage processing on microstructure morphology, post mortem was performed with the help of SEM/EBSD.

As shown in Fig.9(a), a so-called zig-zag shape morphology can be observed in the fracture zone, which is linked to the existence of ductile damage rather than cleavage damage. In order to facilitate the analysis, this fractured sample was divided into 2 parts (marked by L part and $\mathrm{R}$ part), which is shown in upper part of Fig.9(a).

Voids may also stimulate failure by instability, which usually involves one or more shear bands. In order to analyze the failure procedure, it is necessary to select some regions in the vicinity of fracture surface. Fig.9(b)\&(d) presents the microstructure morphology of such selected regions. Microstructure distortion and kinking can be observed in these post mortem micrographs. This could be associated with 
deformation inhomogeneities and involve the existence of shear bands (marked as grain-scale shear band, and pointed out by white arrows). Such regions of high deformation could promote the nucleation and growth of voids (pointed out by blue arrows) along shear bands[41,42].

In the literature, it well documented that slip or shear bands play an important role during plastic deformation processes[43-49]. For instance, at the micro scale, the slip bands[44,47,49] and shear bands[44,46,47-49] can be treated as a symbol of plastic strain localization in Ti alloys, which may relate to nucleation and propagation of local voids. Furthermore, it has been proved that shear bands can be treated as vulnerable sites for nucleation, growth and coalescence of voids in the way of numerical simulation [25] and experiments [49-51].

As shown in Fig.9(b), it can be noticed that voids locate at the inner part of shear band(pointed out by blue arrows), which means that formation of shear band could induce heterogeneous strain distribution and thus motivate inner void nucleation. Moreover, these voids tend to advance along this shear band, which may be induced by occurrence of local shear deformation within this region. If focusing on the area of shear band (rectangle area in Fig.9(b) ), as shown in Fig.9(c), it can be clearly observed that voids prefer to be produced either at the interface of $\alpha$ lamellae and $\beta$ lath (pointed by blue arrows) or the boundary between $\alpha$ colonies (pointed by yellow arrows). 
The same void nucleating behavior could be found in the other part of this specimen, which is shown in Fig.9(d)\&(e). Hence, it can be considered that microscopic inhomogeneities ( $\alpha$ phase and $\beta$ phase) and local plastic incompatibilities ( $\alpha$ colonies with different crystallographic orientations) may trigger the formation of shear bands, and lead to the initiation of voids.
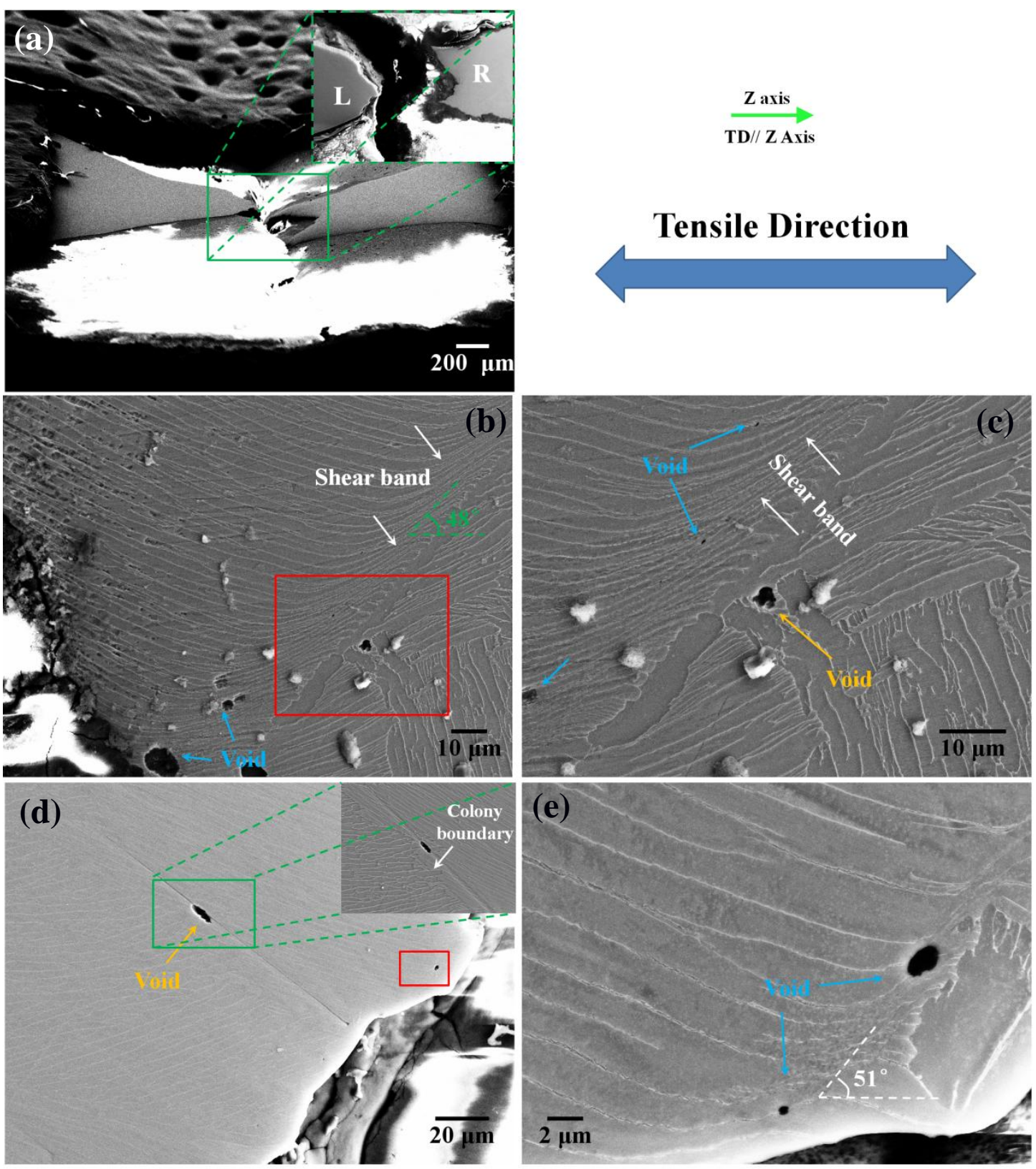

Figure.9 SEM images for central plane of the fractured sample. (a) zig- 
zag fracture shape; (b) microstructure morphology from $\mathrm{R}$ part of the sample;(c) high magnification for selecting region in (b);(d) microstructure morphology from L part of the sample;(e) high magnification for selecting region in (d).

From Fig.10 (a)\&(b), it can be noticed that voids nucleate at the interface of $\alpha / \beta$ phase for both parts of the specimen. In addition, once the embryos of voids form, they will grow in $\alpha$ phase and tend to distribute along $\alpha$ lamellae.
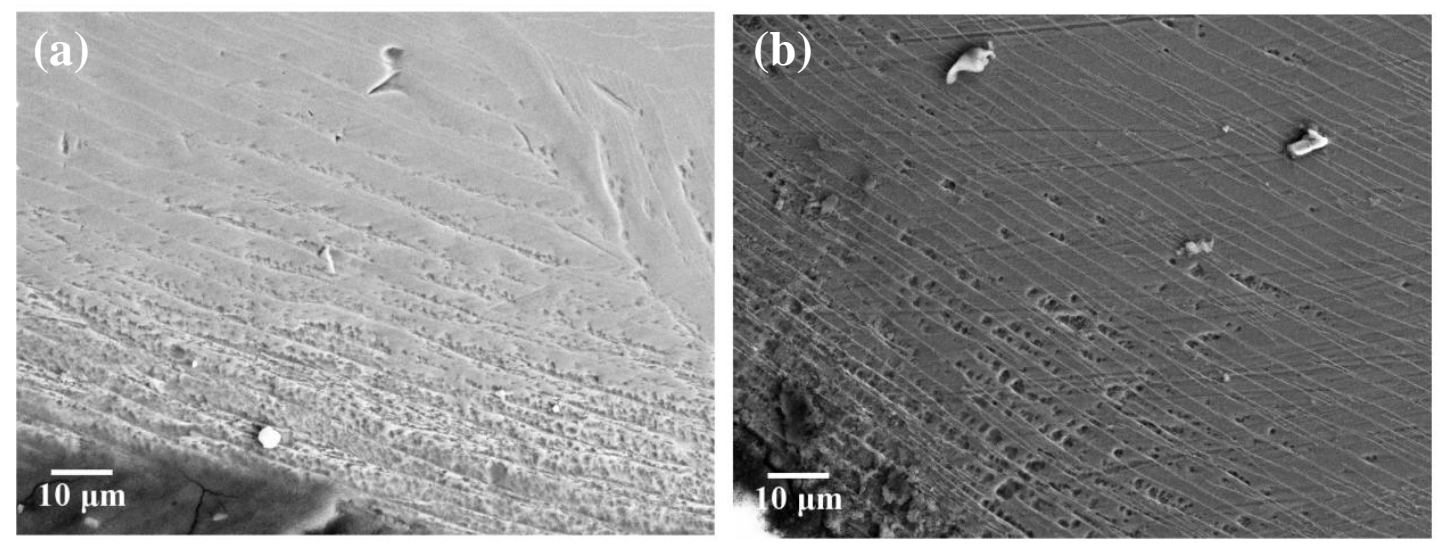

Tensile Direction

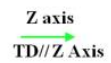

Figure.10 SEM images for the distribution of the voids within one grain.

(a) L part; (b) R part.

In order to understand the interplay between local inhomogeneities and void evolution, EBSD mapping was performed for the regions adjacent to fracture surface. Within these maps (See Fig.11), distinct orientation gradient can be observed, which means that slip is the main deforming mechanism during deformation process.

From Fig.11(a) (c), it can be seen that the fracture trace tends to 
follow the lath boundaries, accompanied with microstructure distortion in the vicinity of ruptured surface. Besides, one crack(marked as crack A) exists in the distorting zone. As shown in Fig.11(d)\&(e), three grains were selected and marked as Grain1, 2 and 3 adjacent to the fracture surface. These grains present a close orientation and tend to align their $<0001>$ axis with the Normal Direction(ND). Moreover, the distortion of the $\alpha$-colonies close to the crack surface can be clearly observed in these three grains, which is in line with SEM image (shown in Fig.11(a)). 

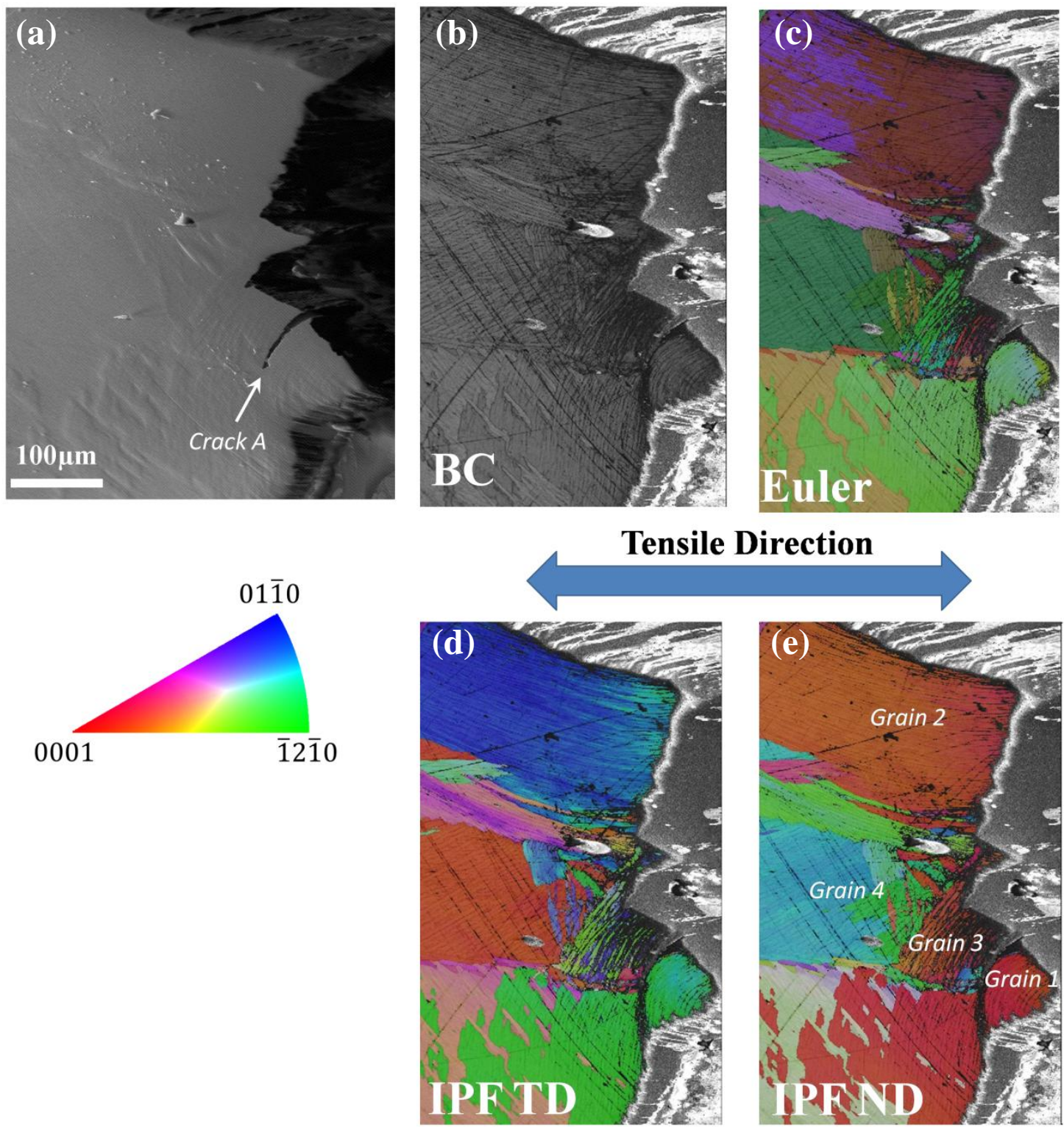

Figure.11 EBSD maps for the fracture region. (a) linked SEM image, (b)

Band Contrast image, (c) Euler map, IPF map in TD (d) and in ND (e). For interpretation of the references to colour in this figure legend, the reader is referred to the web version of this article.

Fig.12 depicts the rotation of these three grains in terms of Inverse Pole Figures. The same type of rotation around $<0001>/ /$ ND axis can be observed for Grain 1, Grain 2 and Grain 3. In addition, for Grain 1 and 
Grain 3, distinct rotating deviation could be noticed in IPF LD and IPF TD, which could refer to different rotating levels for these two grains, even they have rotated to activate the same slip system. This may be resulted from different constraint for grains rotation; and could promote the damage initiation at the boundary of Grain 1 and Grain 3(Crack A).
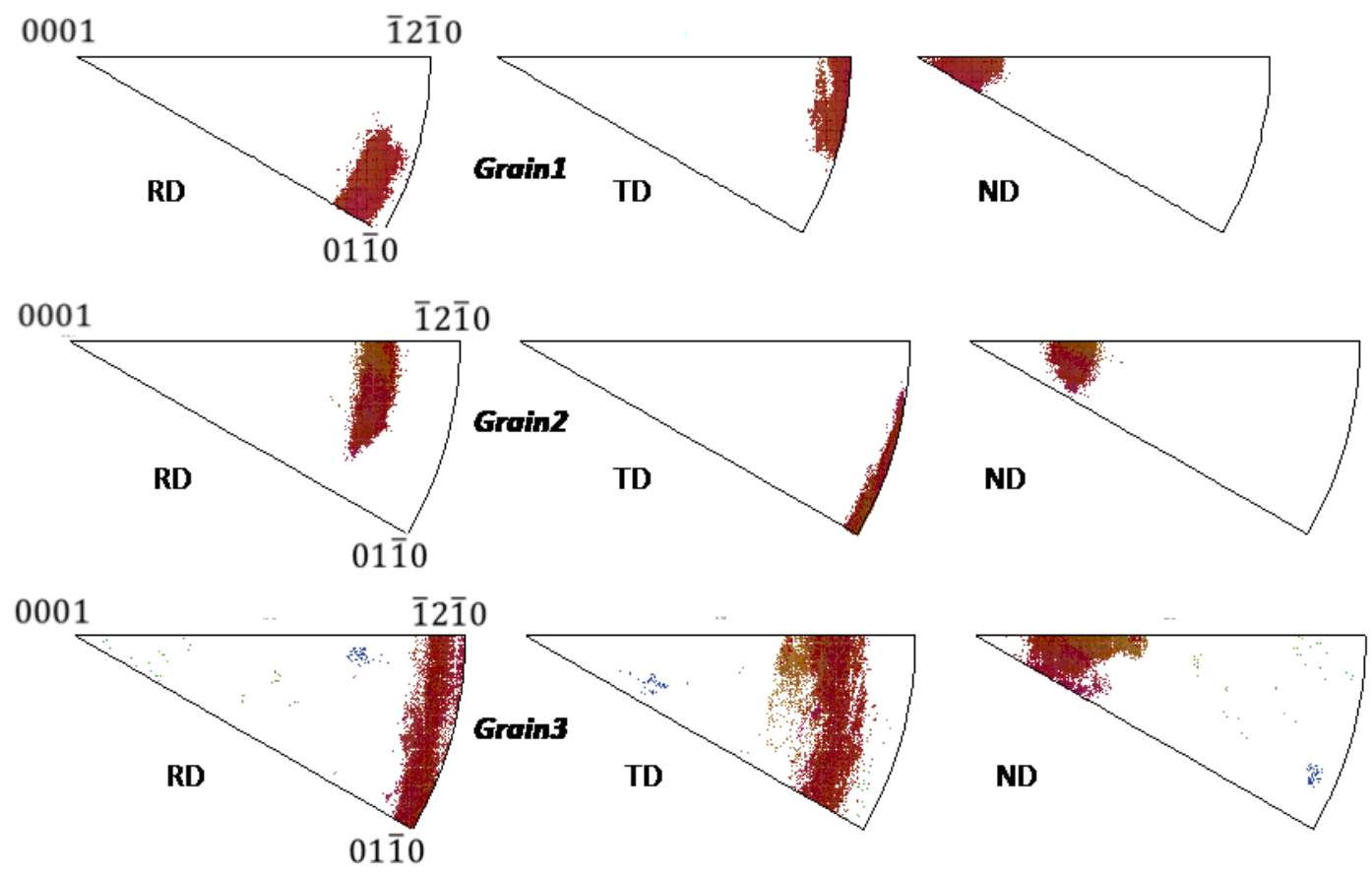

Figure.12 Inverse Pole Figure of Grain 1, 2 and 3 located at the vicinity of fracture surface.

Fig.13 presents the view of the map focusing on the region neighboring to fracture trace (marked by yellow dash line). One grain, which was marked as Grain 4, shows no obvious orientation gradient (grain or colony rotation) inside. This could indicate slip may not occur within in this grain, which may reveal that deformation performs in term 
of twinning rather than slip in Grain 4 . This could be verified by the appearance of deformation twins within this grain(indicated by yellow arrows). But it is worth to notice that no twins can be found in the grains adjacent to the fracture trace(Grain 1, 2 and 3). In other words, slip is the dominating approach during plastic deformation.

\section{Grain 4}
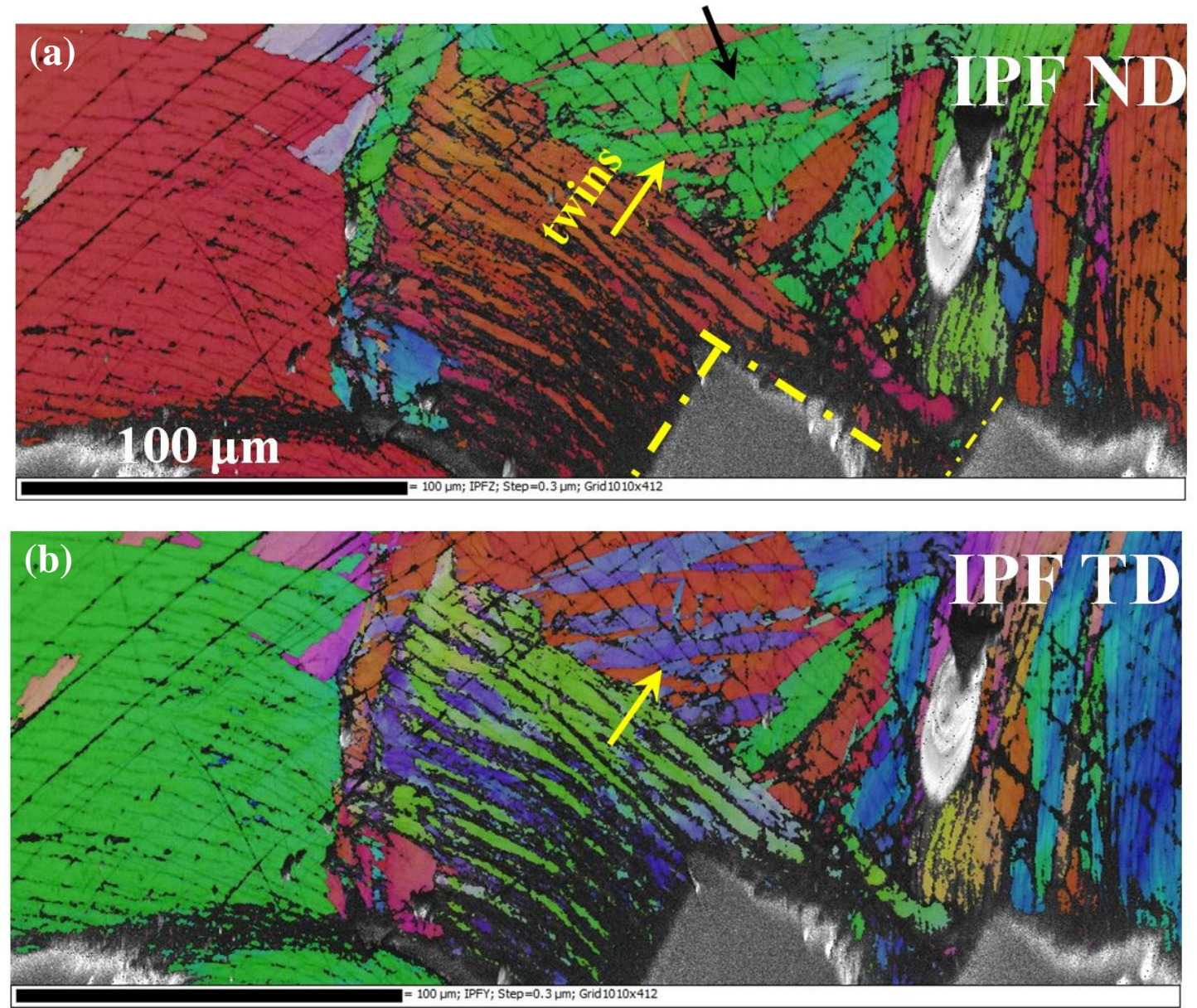

Figure. 13 Closer view of the grain neighboring on the fracture trace, IPF ND map in(a) and TD map in (b). 


\section{Discussion}

Alloys with different microstructure morphologies certainly exhibit different damage mechanisms. From simple morphological arguments (spherical inclusions induce less stress concentration than lamellar ones). It was shown in [5-7] that $\alpha$ Ti alloys or $(\alpha+\beta) \mathrm{Ti}$ alloys with bimodal or equiaxed microstructures exhibit better strength and ductility than the material with a fully lamellar microstructure.

For the alloys with bimodal[11-16] or equiaxed microstructures[17-19], it is known that the precursors of microcracks, voids, tend to nucleate at $\alpha / \beta$ interfaces due to plastic strain incompatibilitites between the two phases. In this situation, stress triaxiality, a significant parameter in damage procedure, may vary seriously during damage development. Besides, Helbert et al[12] have suggested that for Ti-6Al-4V alloy with equiaxed microstructure, under low triaxiality $(\mathrm{T}<0.7)$, voids appear and grow within $\alpha$ particles. For high triaxiality $(T>0.7)$, voids prefer to nucleate at the interface of $\alpha / \beta$ phases.

Whereas, in this work, the result is not consistent with Helbert et al's suggestion[12]. During the whole deformation procedure, stress triaxiality tends to maintain a low and nearly constant value $(0.45<\mathrm{T}<$ 0.55, see Fig.7). But voids prefer to nucleate and propagate at the 
interface of $\alpha / \beta$ phases, within shear bands and grains/colonies boundaries instead of within $\alpha$ phase.

Hence, it is rational to consider that stress triaxiality could not be the dominating factor during damage development in this work. According to experimental results, multi-scale shear stress may play a significant role in void/micro-crack evolution. The influence of shear stress on voids/micro-crack evolution will be interpreted at different scales.

\subsection{Voids initiation and propagation at the interface of $\alpha / \beta$ phase(micro-scale).}

Because of different crystallographic structure for $\alpha$ phase (HCP structure) and $\beta$ phase (BCC structure), different numbers of slip systems can be activated for $\alpha$ phase and $\beta$ phase. This can result in the so-called "plastic deformation incompatibility" and could stimulate the initiation of voids in local region, especially at the interface between $\alpha$ phase and $\beta$ phase. Strain gradient and local stress concentration could evolve during plastic deformation for dual phase $\mathrm{Ti}$ alloys due to this plastic deformation incompatibility of $\alpha$ phase and $\beta$ phase[52-54].

From the literature [55-60], the soft $\alpha$ phase can undertake higher plastic strain than $\beta$ phase. This could lead to dislocation glide and high local strain concentration at the interface. Local shear stress and subsequent local shear band could be generated at the interface, which 
shows in terms of obscure microstructure kink and distortion (see Fig. $10(a) \&(b)$ ). It was treated as "micro-shear band" in order to distinguish it from normal shear band, which linked to microstructure kink obviously(see Fig.9(b)\&(e) ).

Fig.14 (a) (c) illustrate the formation of micro-shear band and evolution of voids. It is worth noting that, because of constraint action from this "hard" straight $\beta$ phase, these micro-shear bands and inclusions, voids, may not be able to rotate in order to respect the highest shear stress direction. This could be testified by the results from Fig.10(a) and Fig.11(c)\&(d).

(a)

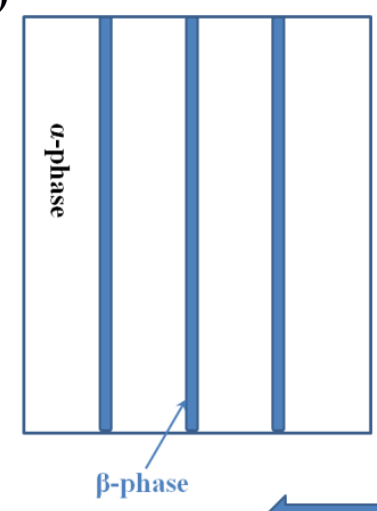

(b)

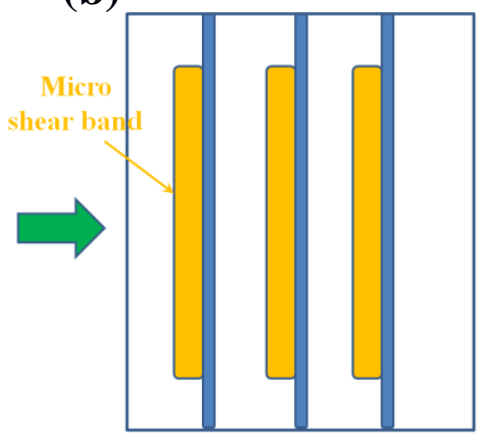

Tensile Direction (c)

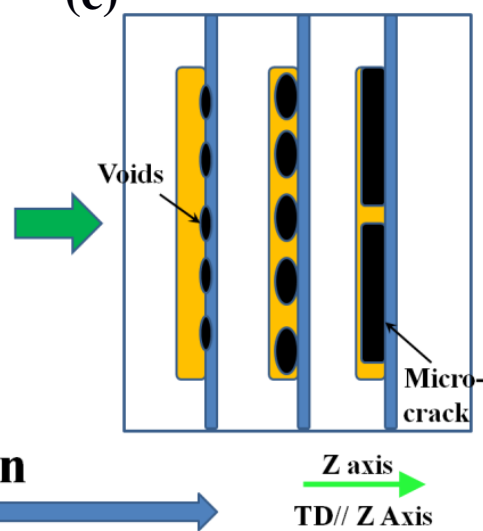

Figure.14 Schematic diagrams of micro-shear band formation and voids evolution during tensile deformation.(a) without loading (b) formation of micro-shear bands (c) initiation of voids. The blue arrow shows the loading direction. 


\subsection{Voids initiation and propagation within the shear bands(grain scale)}

As presented in Fig.9(c) (e), it can be noticed that voids locate within shear band which is in the vicinity of the boundary. As pointed by Q.Xue et al[25], the nucleation of voids can be treated as a result of tensile stress inside shear band. Furthermore, the directions of the shear bands in Fig.9(c) \& (e) tend to tilt from the tensile deforming direction( $\mathrm{Z}$ axis) at an angle of $51^{\circ}$ and $48^{\circ}$, respectively. These are approximately equal to the angle between $\mathrm{Z}$ axis and the direction of highest shear stress in this situation, $45^{\circ}$. Thus, it is rational to infer that the plastic strain localization (shear band) can act as a stimulant to void nucleating at or adjacent to the boundaries.

As for the voids within the shear band, which are shown in Fig.9(d)\&(e), they tend to elongated to elliptical shape along the direction of the shear band, as well as the void located at the boundary (pointed out by yellow arrows in Fig.9(d)). This is due to the existence of severe shear strain within this local region, and consequently, in the subsequent growth and coalescence procedure, these voids can be characterized with elongating to ellipse shape and rotating with respect to the direction of shear band (see Fig.10(f) ).The relationship between shear band and voids evolution are schematically depicted in Fig.15(a) (c).

Before deforming processes, both $\alpha$ lamellae and straight $\beta$ lath can 
be observed without any microstructure distortion (see Fig.15 (a)). When increasing the loading force, because of strain localization, shear bands appear and tend to respect the direction of highest shear stress, as well as the voids nucleation within the shear band(see Fig.15(b) ). Hereafter, voids can contact each other and coalesce to form a micro-crack along this shear band(shown in Fig.15(c) and Fig.9(f) ).

(a)

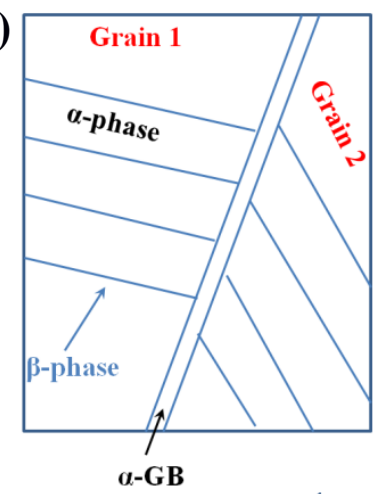

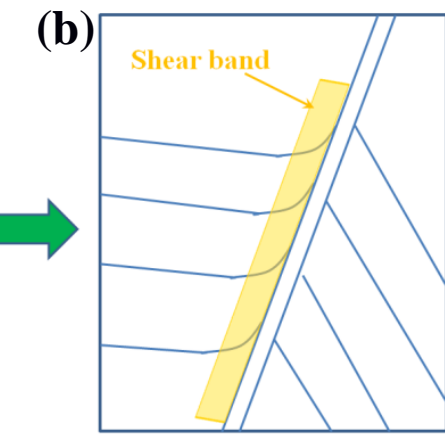

Tensile Direction (c)

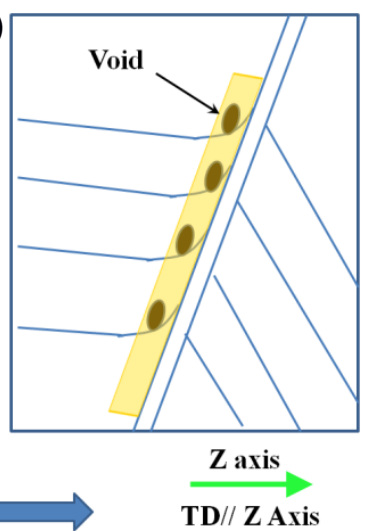

Figure.15 Schematic diagrams of grain-scale shear behavior and its results, shear band formation and voids evolution. (a) Without loading (b) formation of shear bands and voids (c) micro-crack initiation and propagation. The blue arrow shows the loading direction.

\subsection{Voids initiation and propagation at boundaries of grains/colonies(several grains scale)}

If a void prefers to nucleate at the boundary (shown in Fig.9(c)), it may exhibit an elliptical shape and keep its long axis aligning with the boundary. Local shear stress, which can result from serious deforming heterogeneity induced by the discrepancy of crystallographic orientation 
between these neighbor grains/colonies, could induce void evolution at the boundaries(see crack A in Fig.11 ).

In the authors' previous work[26], voids prefer to nucleate at junction of $\alpha$ colonies and grow along the boundary. When plastic deformation occurs, neighbor grains/colonies tend to rotate in order to respect this deformation and to activate slip systems. Since these neighbor grains/colonies have distinct initial crystallographic orientations, they have to rotate to different direction in order to activate slip systems. Hence, severe distorting and shear stress, which could lead to the nucleation of voids, could be generated along the boundary of such neighbor grains/colonies(See Fig.9(b) (d) ). Schematically, the generation of shear stress resulting from grains/colonies and formation of voids was illustrated in Fig.16.

(a)

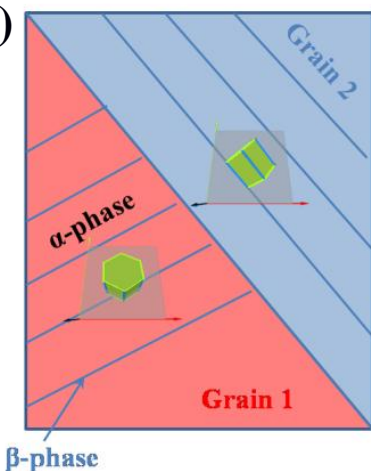

$\beta$-phase

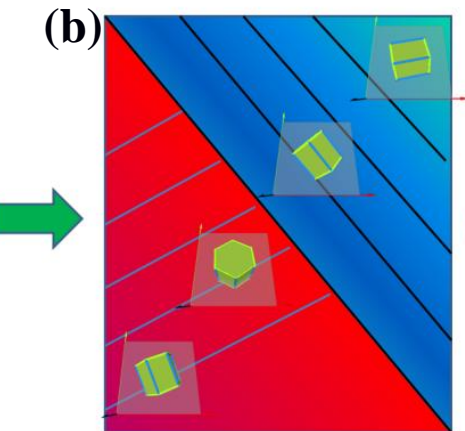

Tensile Direction

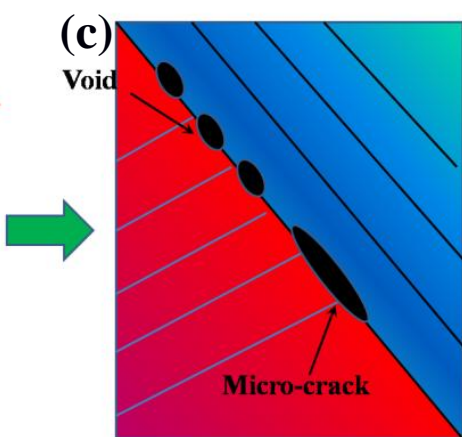

$\mathbf{Z}$ axis

TD// Z Axis

Figure.16 Schematic diagrams of shear behavior formation at boundaries of neighbor grains/colonies. (a) Without loading (b) grains rotation to form shear stress (c) voids initiation and propagation. The blue arrow shows the loading direction. 


\section{Conclusions}

The damage development of Ti-6Al-4V alloy with lamellar microstructure was analyzed by employing in situ tensile test based on Synchrotron X-ray micro tomography. Furthermore, the origins of shear stress generation and role of shear playing in void initiation and propagation was conducted by post mortem using SEM and EBSD techniques. The main conclusions are as follows.

1) For Ti-6Al-4V titanium alloy with full lamellar microstructure, slip is the dominant approach during uniaxial tensile deformation, as a symbol of clear orientation gradient from EBSD map. After deforming, obvious microstructure distortion and kinking can be found, which refers to the existence of severe plastic stress/strain localization in local region.

2) Void, locating at the central region, initiate as soon as the alloy starts to yield. Then, such voids grow towards the direction with an inclining angle from the tensile direction of $23^{\circ}$. Besides, the value of stress triaxiality nearly keeps as a constant during the whole damage development. Therefore, it could be considered shear stress could play a significant role rather than stress triaxiality.

3) Origin of shear stress generation is due to microstructure 
inhomogeneity and consequently, plastic strain localization. Within one grain/colony, this shear stress, which results from deformation incompatibility of $\alpha$ phase and $\beta$ phase, can promote voids initiation along the interface of $\alpha / \beta$ phases. Within the range of one grain, shear band can become the preferred site for nucleation, growth and coalescence of voids. Within the range of 2 3 neighbor grains, during the deformation, formation of shear stress at the boundary could be attributed to the heterogeneous rotation of neighbor grains which exhibit distinct initial crystallographic orientation. This shear stress could "tear" the boundary in order to accommodate voids nucleating along it.

\section{Acknowledgement}

The authors (Ning DANG, Chaoli MA and Lian ZHOU) are grateful to the financial support by International Science and Technology Cooperation Program of China [grant numbers 2015DFA51430], National Natural Science Foundation of China [grant numbers 51671012, 51671007and 51401010] and Aeronautical Science Foundation of China [grant numbers 2015ZF51069] and to carry out this work. Also the author, Ning DANG, would like to thank the China Scholarship Council [grant numbers 201406020005] for financial support. Besides, the authors 
would like to appreciate Prof. Yongmei WANG in BaoTi Group Co.Ltd and Prof. Yingli YANG in Northwest Institute For Non-ferrous Metal Research of providing Ti-6Al-4V alloy. ESRF beam line ID19 is acknowledged for providing beam time.

\section{Data availability}

The raw/processed data required to reproduce these findings cannot be shared at this time as the data also forms part of an ongoing study.

\section{References}

[1] G. Lütjering, J.C. Williams, Introduction, Titanium, Springer Berlin Heidelberg, Berlin, Heidelberg, 2007, pp. 1-14.

[2] D. Banerjee, J.C. Williams, Perspectives on Titanium Science and Technology ,Acta Mater. 61 (2013) 844-879.

[3] M. Peters, J. Kumpfert, C.H. Ward, C. Leyens, Titanium Alloys for Aerospace Applications, Titanium and Titanium Alloys, Wiley-VCH Verlag GmbH \& Co. KGaA, 2005, pp. 333-350.

[4] G.Q. Wu, C.L. Shi, W. Sha, A.X. Sha, H.R. Jiang, Effect of microstructure on the fatigue properties of Ti-6Al-4V titanium alloys, Mater. Des. 46 (2013) 668-674.

[5] A. Attanasio, M. Gelfi, A. Pola, E. Ceretti, C. Giardini, Influence of Material Microstructures in Micromilling of Ti6Al4V Alloy, Mater. 6 (2013) 4268.

[6] S.H.I. Jaffery, M. Khan, N.A. Sheikh, P.T. Mativenga, Wear Mechanism Analysis in Milling of Ti-6Al-4V alloy, Proc. IMechE, Part B: J. Engineering Manufacture 227(2013) 1148-1156.

[7] Y. Fan, W. Tian, Y. Guo, Z. Sun, J. Xu, Relationships among the Microstructure, Mechanical Properties, and Fatigue Behavior in Thin Ti6Al4V, Adv. Mater. Sci. Eng. 2016 (2016) 1-9.

[8] S. Katani, F. Madadi, M. Atapour, S.Z. Rad, Micromechanical modelling of damage behaviour of Ti-6Al-4V, Mater. Des. 49 (2013) 1016-1021.

[9] K.S. Choi, W.N. Liu, X. Sun, M.A. Khaleel, Microstructure-based constitutive modeling of TRIP steel: Prediction of ductility and failure modes under different loading conditions, Acta Mater. 57 (2009) 2592-2604. 
[10] X. Sun, K.S. Choi, W.N. Liu, M.A. Khaleel, Predicting failure modes and ductility of dual phase steels using plastic strain localization, Int. J. of Plast. 25 (2009) 1888-1909.

[11] R. Shi, Z. Nie, Q. Fan, G. Li, Elastic plastic deformation of TC6 titanium alloy analyzed by in-situ synchrotron based X-ray diffraction and microstructure based finite element modeling, J. Alloy. Compds. 688 (2016) 787-795.

[12] A.L. Helbert, X. Feaugas, M. Clavel, The influence of stress trlaxiality on the damage mechanisms in an equiaxed $\alpha / \beta$ Ti-6AI-4V alloy, Metall. Mater. Trans. A. 27 (1996) 3043-3058.

[13] L. Lecarme, E. Maire, K.C.A. Kumar, C. De Vleeschouwer, L. Jacques, A. Simar, T. Pardoen, Heterogenous void growth revealed by in situ 3-D X-ray microtomography using automatic cavity tracking, Acta Mater. 63 (2014) 130-139.

[14] X.C. Zhang, F. Zhong, J.B. Shao, C.C. Zhang, N.X. Hou, G.J. Yuan, S.T. Tu, Failure mechanism and mode of Ti-6Al-4V alloy under uniaxial tensile loading: Experiments and micromechanical modeling, Mater. Sci. Eng: A 676 (2016) 536-545.

[15] J. Kumar, B. Srivathsa, V. Kumar, Stress triaxiality effect on fracture behavior of IMI-834 titanium alloy: A micromechanics approach, Mater. Des. 30 (2009) 11181123.

[16] T.P. Chapman, K.M. Kareh, M. Knop, T. Connolley, P.D. Lee, M.A. Azeem, D. Rugg, T.C. Lindley, D. Dye, Characterisation of short fatigue cracks in titanium alloy IMI 834 using X-ray microtomography, Acta Mater. 99 (2015) 49-62.

[17] S.L. Semiatin, V. Seetharaman, A.K. Ghosh, E.B. Shell, M.P. Simon, P.N. Fagin, Cavitation during hot tension testing of Ti-6Al-4V, Mater. Sci. Eng: A 256 (1998) 92-110.

[18] T.R. Bieler, P.D. Nicolaou, S.L. Semiatin, An experimental and theoretical investigation of the effect of local colony orientations and misorientation on cavitation during hot working of Ti-6Al-4V, Metal. Mater. Trans. A. 36 (2005) 129.

[19] A. Pineau, A.A. Benzerga, T. Pardoen, Failure of metals I: Brittle and ductile fracture, Acta Mater. 107 (2016) 424-483.

[20] S.K. Paul, Real microstructure based micromechanical model to simulate microstructural level deformation behavior and failure initiation in DP 590 steel, Mater. Des. 44 (2013) 397-406.

[21] S.K. Paul, A. Kumar, Micromechanics based modeling to predict flow behavior and plastic strain localization of dual phase steels, Comp. Mater. Sci. 63 (2012) 66-74. [22] S. Sodjit, V. Uthaisangsuk, Microstructure based prediction of strain hardening behavior of dual phase steels, Mater. Des. 41 (2012) 370-379.

[23] M. Ohata, M. Suzuki, A. Ui, F. Minami, 3D-Simulation of ductile failure in twophase structural steel with heterogeneous microstructure, Eng. Fract. Mech. 77 (2010) 277-284.

[24] S.K. Paul, Micromechanics based modeling of Dual Phase steels: Prediction of ductility and failure modes, Comp. Mater. Sci. 56 (2012) 34-42.

[25] Q. Xue, M.A. Meyers, V.F. Nesterenko, Self-organization of shear bands in titanium and Ti-6Al-4V alloy, Acta Mater. 50 (2002) 575-596.

[26] N. Dang, L. Liu, E. Maire, J. Adrien, S. Cazottes, W. Xiao, C. Ma, 1. Zhou, 3D 
X-ray Tomographic analysis of crack nucleation and growth by void coalescence in an $\alpha / \beta$ Ti alloy lamellar microstructure, Mater. Sci. Eng:A. (2018) (Under Review).

[27] E. Maire, O. Bouaziz, M. Di Michiel, C. Verdu, Initiation and growth of damage in a dual-phase steel observed by X-ray microtomography, Acta Mater. 56 (2008) 4954-4964.

[28] M. Herbig, A. King, P. Reischig, H. Proudhon, E.M. Lauridsen, J. Marrow, J.-Y. Buffière, W. Ludwig, 3-D growth of a short fatigue crack within a polycrystalline microstructure studied using combined diffraction and phase-contrast X-ray tomography, Acta Mater. 59 (2011) 590-601.

[29] C. Landron, E. Maire, O. Bouaziz, J. Adrien, L. Lecarme, A. Bareggi, Validation of void growth models using X-ray microtomography characterization of damage in dual phase steels, Acta Mater. 59 (2011) 7564-7573.

[30] J.Y. Buffiere, E. Maire, J. Adrien, J.P. Masse, E. Boller, In Situ Experiments with X ray Tomography: an Attractive Tool for Experimental Mechanics, Exp. Mech. 50 (2010) 289-305.

[31] E. Maire, V. Carmona, J. Courbon, W. Ludwig, Fast X-ray tomography and acoustic emission study of damage in metals during continuous tensile tests, Acta Mater. 55 (2007) 6806-6815.

[32] M. Suéry, J. Adrien, C. Landron, S. Terzi, E. Maire, L. Salvo, J.-J. Blandin, Fast in-situ X-ray micro tomography characterisation of microstructural evolution and strain-induced damage in alloys at various temperatures, Int. J. Mater. Res. 101 (2010) 1080-1088.

[33] F. Bron, J. Besson, A. Pineau, Ductile rupture in thin sheets of two grades of 2024 aluminum alloy, Mater. Sci. Eng: A 380 (2004) 356-364.

[34] C. Landron, O. Bouaziz, E. Maire, J. Adrien, Characterization and modeling of void nucleation by interface decohesion in dual phase steels, Scripta Mater. 63 (2010) 973-976.

[35] T. Pardoen, F. Delannay, Assessment of void growth models from porosity measurements in cold-drawn copper bars, Metall. Mater. Trans. A 29 (1998) 18951909.

[36] B. Beausir, J.-J. Fundenberger, Université de Lorraine - Metz, 2015, ATOM Analysis Tools for Orientation Maps, http://atom-software.eu/

[37] P.W. Bridgman, Effects of High Hydrostatic Pressure on the Plastic Properties of Metals, Rev. Mod. Phys. 17 (1945) 3-14.

[38] J.R. Rice, D.M. Tracey, On the ductile enlargement of voids in triaxial stress fields, J. Mech. Phys. Solid. 17 (1969) 201-217.

[39] A.L. Gurson, Continuum Theory of Ductile Rupture by Void Nucleation and Growth : Part 1-Yield Criteria and Flow Rules for Porous Ductilr Media, J. Eng. Mater. Tech. 99 (1975) 297-300.

[40] V. Tvergaard, A. Needleman, Analysis of the cup-cone fracture in a round tensile bar, Acta Metall. 32 (1984) 157-169.

[41] A.A. Benzerga, J. Besson, A. Pineau, Anisotropic ductile fracture : Part I: experiments, Acta Mater. 52 (2004) 4623-4638.

[42] L. Anand, W.A. Spitzig, Initiation of localized shear bands in plane strain, J. 
Mech. Phys. Solid. 28 (1980) 113-128.

[43] D. Qin, Y. Lu, Q. Liu, L. Zheng, L. Zhou, Transgranular shearing introduced brittlement of $\mathrm{Ti}-5 \mathrm{Al}-5 \mathrm{~V}-5 \mathrm{Mo}-3 \mathrm{Cr}$ alloy with full lamellar structure at room temperature, Mater. Sci. Eng: A572 (2013) 19-24.

[44] M. Zhang, F. Bridier, P. Villechaise, J. Mendez, D.L. McDowell, Simulation of slip band evolution in duplex Ti-6Al-4V, Acta Mater. 58 (2010) 1087-1096.

[45] C. Huang, Y. Zhao, S. Xin, W. Zhou, Q. Li, W. Zeng, Effect of microstructure on tensile properties of Ti-5Al-5Mo-5V-3Cr-1Zr alloy, J. Alloy. Compds.693 (2017) 582-591.

[46] P. Castany, F. Pettinari-Sturmel, J. Douin, A. Coujou, .In situ transmission electron microscopy deformation of the titanium alloy $\mathrm{Ti}-6 \mathrm{Al}-4 \mathrm{~V}$ : Interface behavior, Mater. Sci. Eng: A 483 (2008) 719-722.

[47] J.L. Sun, P.W. Trimby, F.K. Yan, X.Z. Liao, N.R. Tao, J.T. Wang, Shear banding in commercial pure titanium deformed by dynamic compression, Acta Mater. 79 (2014) 47-58.

[48] S. Wang, Y. Zhang, C. Schuman, J.S. Lecomte, X. Zhao, L. Zuo, M.J. Philippe, C. Esling, Study of twinning/detwinning behaviors of Ti by interrupted in situ tensile tests, Acta Mater. 82 (2015) 424-436.

[49] Y.M. Ren, X. Lin, X. Fu, H. Tan, J. Chen, W.D. Huang, Microstructure and deformation behavior of Ti-6Al-4V alloy by high-power laser solid forming, Acta Mater. 132 (2017) 82-95.

[50] S.D. Antolovich, R.W. Armstrong, Plastic strain localization in metals: origins and consequences, Prog. Mater. Sci. 59 (2014) 1-160.

[51] D. Qin, Y. Lu, D. Guo, L. Zheng, Q. Liu, L. Zhou, Tensile deformation and fracture of $\mathrm{Ti}-5 \mathrm{Al}-5 \mathrm{~V}-5 \mathrm{Mo}-3 \mathrm{Cr}-1.5 \mathrm{Zr}-0.5 \mathrm{Fe}$ alloy at room temperature, Mater. Sci. Eng: A 587 (2013) 100-109.

[52] S. Ankem, H. Margolin, The role of elastic interaction stresses on the onset of plastic flow for oriented two ductile phase structures, Mater.Trans.A. 11 (1980) 963.

[53] S. Ankem, H. Margolin, A rationalization of stress-strain behavior of two-ductile phase alloys ,Mater.Trans.A. 17 (1986) 2209-2226.

[54] M.F. Ashby, The deformation of plastically non-homogeneous materials, Phil. Mag. 21 (1970) 399-424.

[55] C. Tan, Q. Sun, L. Xiao, Y. Zhao, J. Sun, Slip transmission behavior across $\alpha / \beta$ interface and strength prediction with a modified rule of mixtures in TC21 titanium alloy, J. Alloy. Compds. 724 (2017) 112-120.

[56] K.S. Chan, Y.D. Lee, Effects of Deformation-Induced Constraint on High-Cycle Fatigue in Ti Alloys with a Duplex Microstructure, Metall. Mater. Trans. 39 (2008) 1665-1675.

[57] C. Tan, Q. Sun, L. Xiao, Y. Zhao, J. Sun, Cyclic Deformation and Microcrack Initiation During Stress Controlled High Cycle Fatigue of a Titanium Alloy, Mater. Sci. Eng:A 711 (2018)212-222.

[58] K.S. Chan, Changes in fatigue life mechanism due to soft grains and hard particles, Int. J. Fatigue 32 (2010) 526-534.

[59] K. Hashimoto, H. Margolin, The role of elastic interaction stresses on the onset 
of slip in polycrystalline alpha brass-I. Experimental determination of operating slip systems and qualitative analysis, Acta Metall. 31 (1983) 773-785.

[60] C. Tan, X. Li, Q. Sun, L. Xiao, Y. Zhao, J. Sun, Effect of $\alpha$-phase morphology on low-cycle fatigue behavior of TC21 alloy, Int. J. Fatigue 75 (2015) 1-9. 